\title{
Dynamic Changes to Endogenous Germination Inhibitors in Cercis chinensis Seeds during Dormancy Release
}

\author{
Yunpeng Gao, Mingwei Zhu, Haoyu Wang, and Shuxian Li \\ Co-Innovation Center for Sustainable Forestry in Southern China, \\ College of Forestry, Nanjing Forestry University, Nanjing 210037, China
}

Additional index words. Cercis chinensis, endogenous inhibitors, GC-MS, HPLC, quantitative analysis, seed dormancy

\begin{abstract}
The purpose of this study was to determine whether Cercis chinensis seeds contain endogenous germination inhibitors, and if so, to clarify the dynamic changes to the inhibitors during dormancy release. A cabbage seed germination test was conducted to assess the seed extract activities during dormancy release. The endogenous inhibitor components were analyzed by gas chromatography-mass spectrometry and the dynamic changes to the endogenous inhibitors were analyzed by high-performance liquid chromatography. The analyses revealed 1,2,3-benzenetriol (phenolic compound) in the seedcoat is a water-soluble endogenous inhibitor, and the $I C_{50}$ (the concentration at which 1,2,3-benzenetriol inhibited radicle growth of cabbage seeds by $50 \%$ ) of $1,2,3$-benzenetriol was $51.2 \mu \mathrm{g} \cdot \mathrm{mL}^{-1}$. During dormancy release, the seed 1,2,3-benzenetriol content decreased to $17.7 \mu \mathrm{g} \cdot \mathrm{mL}^{-1}$ (stratified for 60 days) from $561.4 \mu \mathrm{g} \cdot \mathrm{mL}^{-1}$ (control). The abscisic acid (ABA) content exhibited the same tendency, decreasing from $5.6 \mathrm{ng} \cdot \mathrm{mL}^{-1}$ to $0.5 \mathrm{ng} \cdot \mathrm{mL}^{-1}$ after 60 -day stratification. Exogenous ABA was highly inhibitory toward cabbage seed germination, with an $I C_{50}$ of 1.5 $\mathrm{ng} \cdot \mathrm{mL}^{-1}$. These results indicate that $\mathrm{ABA}$ and 1,2,3-benzenetriol are important endogenous inhibitors in $C$. chinensis seeds, wherein they regulate seed dormancy, even at low concentrations.
\end{abstract}

Seed dormancy refers to the state in which an intact viable seed does not complete germination under favorable conditions (Finch-Savage and Leubner-Metzger, 2006). Normally, the dormancy is influenced by the embryo and its surrounding layers (e.g., seed coat and endosperm). Previous studies revealed that germination is a complex process and the presence of endogenous inhibitors is the major reason for the physiological dormancy in many plants (Paiva and Prudente, 2018; Samajdar et al., 2018). For example, the seeds of Trillium kamtschaticum (Shao et al., 2016) and Taxus yunnanensis (Bian et al., 2018) contain endogenous inhibitors whose contents gradually decrease during dormancy release. Earlier research proved that $\mathrm{ABA}$ is an endogenous inhibitor in the

Received for publication 22 Jan. 2021. Accepted for publication 23 Feb. 2021.

Published online 30 April 2021.

This research was supported by the Natural Science Foundation of China (31770674), the Innovative Research Team of the Universities of Jiangsu Province, the Innovative Research Team of the Educational Department of China, and the Priority Academic Program Development of Jiangsu Higher Education Institutions.

S.L. is the corresponding author. E-mail: shuxianli@njfu.com.cn.

This is an open access article distributed under the CC BY-NC-ND license (https://creativecommons. org/licenses/by-nc-nd/4.0/) seeds of Arabidopsis thaliana (Chen et al., 2019), Leymus chinensis ( $\mathrm{Hu}$ et al., 2012), and Avena sativa (Poljakoff-Mayber et al., 2002). Martinucci et al. (1985) reported that ferulic acid is the most important factor affecting the dormancy of Cercis siliquastrum seeds. In walnut seeds, phenolics are believed to inhibit germination (Matok et al., 2009). In addition, organic acids, polyphenolic compounds, flavonoids, and alkaloids have been identified as potential inhibitors (Samajdar et al., 2018).

Chinese redbud (Cercis chinensis), which belongs to the family Caesalpiniaceae, is native to China and Japan (Li, 1944). It is an important spring-flowering tree species because of its showy flowers that remain on trees for 2 to 3 weeks (Robertson, 1976). In addition to its application as a landscape plant, it also has important medicinal uses. Specific substances extracted from the bark of $C$. chinensis trees are used in traditional medicine to activate blood circulation and alleviate swelling. Moreover, the flowers are used for treating rheumatic arthritis (Wang et al., 2009; Zhang et al., 2011).

C. chinensis is mainly propagated via seeds, but the strong dormancy of its seeds, which need to be stratified for more than 2 months to release dormancy, is a major factor restricting propagation. Previous studies indicated that excised embryos can germinate, but endogenous inhibitors in the seedcoat and the thin layer of nucellar remnants (endosperm) maintain the dormancy of $C$. chinensis seeds (Zhou, 2016). The composition of the endogenous inhibitors in the seeds remains unknown. Thus, in this study, $C$. chinensis seed extracts were analyzed by gas chromatography-mass spectrometry (GC-MS) to precisely identify the substances inhibiting $C$. chinensis seed germination. In addition, the localization of the endogenous inhibitors was clarified. The results of this research will provide valuable information for elucidating the reproductive physiology of $C$. chinensis seeds as well as the regulatory mechanism of strongly dormant seeds.

\section{Materials and Methods}

Seed source. Desiccated $C$. chinensis pods were collected in Nov. 2017 at Nanjing Forestry University, Jiangsu Province, China. Seeds were manually removed from pods, and those undamaged by insects were retained for the subsequent experiments. After drying at room temperature $\left(25^{\circ} \mathrm{C}\right)$ for 1 week, the seeds were stored at $4^{\circ} \mathrm{C}$ until analyzed. The mean 1000-seed weight was 25.9 $\mathrm{g}$ and the moisture content was $12.7 \%$.

Preparing $C$. chinensis seed extracts. $C$. chinensis seeds were immersed in water at $80^{\circ} \mathrm{C}$ for $5 \mathrm{~min}$ and then gradually cooled to room temperature for $24 \mathrm{~h}$ to soften seeds. The swollen seeds were stratified at $4{ }^{\circ} \mathrm{C}$ in moistened sand to break physiological dormancy. During the cold stratification, water was added as needed to keep seeds moist. Seeds were collected at $0,15,30,45$, and 60 $\mathrm{d}$ after initiating the stratification. They were then placed in a sieve and rinsed under running water, after which they were lyophilized in a vacuum freeze dryer (Martin Christ, Osterode, Germany) and ground to powder in liquid nitrogen. The powder corresponding to $\approx 35$ seeds $(1.0 \mathrm{~g})$ was mixed with $50 \mathrm{~mL}$ $100 \%$ methanol [high-performance liquid chromatography (HPLC) grade] in a conical flask, which was covered with parafilm to prevent evaporation. An ultrasonic extraction was completed in $30 \mathrm{~min}$ with an ultrasonic cleaning bath at room temperature $(25 \pm$ $\left.1{ }^{\circ} \mathrm{C}\right)$. The extract was filtered through a membrane with $0.45-\mu \mathrm{m}$ pores (Sangon Biotech, Shanghai, China) and the ultrasonic extraction was performed two more times with the residue. The three methanol extracts were combined and evaporated at $40^{\circ} \mathrm{C}$ to $\approx 12$ $\mathrm{mL}$ under vacuum conditions in the RE-3000 Rotary Evaporator (Yarong Biochemical Instrument Factory, Shanghai, China) to remove the methanol. The extract was filtered as described previously.

Bioassay activities of seed extracts during dormancy release. Changes to the endogenous inhibitor activities of the $C$. chinensis seeds during cold stratification were assessed by incubating three replicates of 100 nondormant Chinese cabbage (Brassica chinensis) seeds in the prepared extracts. Specifically, the seeds were soaked in $1.0 \mathrm{~mL} C$. chinensis seed extracts or distilled water (control) for 3 h. Next, $1.0-\mathrm{mL}$ extracts or distilled water 
were applied to filter paper (9-cm diameter) placed in petri dishes (9-cm diameter). After the organic solvent had completely volatilized, $5 \mathrm{~mL}$ distilled water was added to each dish. The culture dishes containing cabbage seeds were incubated in the LRH-300-G Illumination Incubator (Jiufo-electric, Guangzhou, China) set at $25^{\circ} \mathrm{C}$ with an 8 -h (light)/ 16-h (dark) photoperiod. The number of normal seedlings was recorded daily for up to 7 $\mathrm{d}$ following the International Seed Testing Association rules (ISTA, 2020). The germination percentage was calculated based on the percentage of normal seedlings, after which the decline in germination percentage (DGP) was calculated with the following equation (Zhao et al., 2018):

$$
D G P(\%)=\frac{G P_{\text {Control }}-G P_{\text {Treatment }}}{G P_{\text {Control }}}
$$

$$
\times 100,
$$

where $G P_{\text {Control }}$ and $G P_{\text {Treatment }}$ are the germination percentages of the Chinese cabbage seeds treated with distilled water and C. chinensis seed extracts, respectively.

Changes to the relative endogenous inhibitor contents of the $C$. chinensis seedcoat and endosperm as determined by GC-MS. When the $C$. chinensis seeds were stratified for 45 $\mathrm{d}$, no more than $5 \%$ of the seeds germinated. Therefore, the seedcoat and endosperm were separated from the dormant $(0 \mathrm{~d})$ and treated (stratified for 45 d) C. chinensis seeds. Extracts were prepared for the seedcoat and endosperm with the methanol solution, as described previously. Regarding the GC-MS analysis, the extract components were esterified to the more volatile methyl esters via a slightly modified version of a published methanol- $\mathrm{BF}_{3}$ method (Botinestean et al., 2012). Changes to the relative endogenous inhibitor contents of the seedcoat and endosperm were analyzed with the GC-6890N gas chromatograph (Agilent, Palo Alto, CA) coupled with the MS-5973 mass selective detector (Agilent). A PEG-20M column (30 m $\times$ $0.32 \mathrm{~mm}$ internal diameter, $0.25 \mu \mathrm{m}$ film thickness) was used for the GC-MS analysis. The GC oven temperature was initially held at $50{ }^{\circ} \mathrm{C}$ for $2 \mathrm{~min}$, after which it was increased to $280^{\circ} \mathrm{C}$ at $5^{\circ} \mathrm{C} \cdot \mathrm{min}^{-1}$ and then maintained for $30 \mathrm{~min}$. Helium was used as the carrier gas at a constant flow rate of 1 $\mathrm{mL} \cdot \mathrm{min}^{-1}$. The MS involved a $70-\mathrm{eV}$ electron ionization, with a receiving current of $300 \mu \mathrm{A}$ and an emission current of $1 \mathrm{~mA}$. The scan range was $10-500 \mathrm{~m} / \mathrm{z}$.

Determining the $I_{50}$ of endogenous inhibitors. ABA and 1,2,3-benzenetriol, which were used as standards, were purchased from Sigma-Aldrich (Darmstadt, Germany). To prepare standard solutions, 1,2,3-benzenetriol was dissolved in distilled water at concentrations of $1,10,100,1000$, and 10,000 $\mu \mathrm{g} \cdot \mathrm{mL}^{-1}$ and ABA was dissolved in methanol at concentrations of $1,5,10,20$, and 50 $\mathrm{ng} \cdot \mathrm{mL}^{-1}$. Each treatment was completed with three replicates of 100 cabbage seeds each. Specifically, $5.0 \mathrm{~mL}$ solution or distilled water (control) was applied to filter paper placed in petri dishes. After adding the cabbage seeds, the petri dishes were incubated in a growth chamber set at $25^{\circ} \mathrm{C}$ with an 8-h (light)/16-h (dark) photoperiod. Following the ISTA (2020) guidelines, the germinated seeds should be normal seedlings. The radicle of cabbage seed was very sensitive to endogenous germination inhibitors, which mainly influenced radicle elongation. Therefore, the length of the cabbage radicle after $72 \mathrm{~h}$ was measured to evaluate the degree of inhibition. The inhibitory rate (\%) was calculated with the following equation as described by Nasrin et al. (2016):

$$
\mathrm{I} \%=\frac{\mathrm{A}_{0}-\mathrm{A}_{1}}{\mathrm{~A}_{0}} \times 100,
$$

where $A_{0}$ is the average radicle length of the control samples and $A_{1}$ is the average radicle length of the treated samples after $72 \mathrm{~h}$.

The $I C_{50}$ was calculated using the linear relation between inhibition rate and the concentration logarithm according to Zhao et al. (2018).

Quantification of endogenous inhibitors in C. chinensis seeds during dormancy release by HPLC. The phenolic contents during the seed stratification were analyzed with the Waters Alliance e2695 HPLC system (Waters, Milford, MA). Specifically, $1.0 \mathrm{~g}$ powder of $C$. chinensis seeds collected at five stratification stages $(0,15,30,45$, and $60 \mathrm{~d})$ were extracted by immersing methanol solution and evaporated as described previously; $2-\mu \mathrm{L}$ extracts were injected into the ZORBAX-SB column $(250 \mathrm{~mm} \times 4.6 \mathrm{~mm}$ internal diameter, $5 \mu \mathrm{m}$ film thickness). The mobile phase comprised $40 \%$ methanol (A) and $60 \%$ distilled water $(\mathrm{B})$, with a $10-\mathrm{min}$ isocratic elution at a flow rate of $1 \mathrm{~mL} \cdot \mathrm{min}^{-1}$. The oven temperature was set at $35^{\circ} \mathrm{C}$. The 1,2,3-benzenetriol peak was detected at 280 $\mathrm{nm}$. The analyzed substances were quantified based on the calibration curves for the purified compounds.

Quantification of endogenous $A B A$ in $C$. chinensis seeds during dormancy release. To quantify the endogenous ABA level during dormancy release, $C$. chinensis seeds collected at specific stratification stages were frozen in liquid nitrogen and ground to a powder in an ice-cooled mortar. The ground samples of $1.0 \mathrm{~g}$ were mixed with $10 \mathrm{~mL}$ isopropanol/ hydrochloric acid extraction buffer, after which $8 \mu \mathrm{L} 1 \mu \mathrm{g} \cdot \mathrm{mL}^{-1}$ ABA (Sigma-Aldrich, Darmstadt, Germany) was added as an internal standard. The solution was shaken for 30 min at $4{ }^{\circ} \mathrm{C}$ and then $20 \mathrm{~mL}$ dichloromethane was added. After shaking the solution for an additional $30 \mathrm{~min}$ at $4{ }^{\circ} \mathrm{C}$, it was centrifuged $\left(12,000 g_{n}\right)$ for $5 \mathrm{~min}$ at $4{ }^{\circ} \mathrm{C}$. Then the supernatant was removed. The organic phase in the lower layer was collected and dried in nitrogen in darkness, after which the ABA concentration was determined with an internal standard method. First, the samples were dissolved with $400 \mu \mathrm{L}$ methanol (HPLC grade) and $2 \mu \mathrm{L}$ of each extract was analyzed with the 1290 HPLC system (Agilent) coupled with the QTRAP 6500 mass spectrometer (PE Sciex, Concord, Canada). A Poroshell 120SB column $(150 \mathrm{~mm} \times 2.1 \mathrm{~mm}$ internal diameter, $2.7 \mu \mathrm{m}$ film thickness) was used for the HPLC-MS system. The mobile phase consisted of a binary solvent system with methanol acidified with $0.1 \%$ formic acid (solvent A) and water acidified with $0.1 \%$ formic acid (solvent B). The column was maintained at $30^{\circ} \mathrm{C}$. The gradient program started with $20 \%$ solvent A for 1 min followed by a linear increase to $80 \%$ in $8 \mathrm{~min}$. The solvent A percentage was maintained for $1 \mathrm{~min}$, after which solvent A was increased linearly to $20 \%$ in $0.1 \mathrm{~min}$ and held for 5 min. Regarding the quantitative analysis of ABA by HPLC-MS, the characteristic ion pair 263.1/204.2 was monitored. The ABA contents were calculated by comparing the ratio of the area under the peaks of 204.2 and 263.1 derived from a known amount of deuterated ABA.

Statistical analysis. Data were analyzed with the SPSS software package (version 22.0; IBN Corp., Armonk, NY; http://www. spss.com/) and the Excel software (Office 2016; Microsoft Corporation, Redmond, WA). One-way analysis of variance followed by Duncan's multiple range test for the variation in treatment means and $P$ values $\leq 0.05$ were considered as the level of significance.

\section{Results}

Changes to endogenous inhibitor activities during dormancy release. C. chinensis seeds did not germinate completely after being stratified for 0,15 , and $30 \mathrm{~d}$. However, when the stratification was extended to 45 and 60 d, $3 \%$ and $100 \%$ of the $C$. chinensis seeds germinated, respectively. A bioassay of endogenous germination inhibitors in extracts prepared from $C$. chinensis seeds collected at different stratification stages was performed using the nondormant Chinese cabbage seeds (Table 1). The data revealed that the nonstratified seeds (i.e., $0 \mathrm{~d}$ ) had the strongest inhibitory effect, with a cabbage seed germination percentage of $39.2 \%$, which was substantially lower than the control germination percentage $(92.0 \%)$. This result indicated that mature C. chinensis seeds had some strong inhibitory substances, which played an important role during dormancy releasing. The cabbage seed germination percentage gradually increased as the stratification period was extended. For example, when the cabbage seeds were treated with the extracts of $C$. chinensis seeds stratified for $60 \mathrm{~d}$, the germination percentage $(90.7 \%)$ was only slightly lower than the control germination percentage $(92.0 \%)$. These results indicated that the extracts of seeds stratified for $60 \mathrm{~d}$ had no inhibitory effect on cabbage seed germination and the $C$. chinensis seed dormancy had been broken.

Changes to the relative endogenous inhibitor contents of the $C$. chinensis endosperm and seedcoat. The results of the GC-MS analysis of compounds in the extracts of the control (nonstratified; $0 \mathrm{~d}$ ) and treated (stratified for $45 \mathrm{~d}) C$. chinensis endosperms are 
presented in Fig. 1. In addition, the compounds are listed in Table 2 in the order of their elution from the PEG-20M column. A total of 14 volatile compounds were identified in the endosperm. Compared with the control levels, the relative contents of the following six compounds decreased during dormancy release: sucrose, 1,6-anhydro- $\beta$-Dglucopyranose, 3-(3-pyridyl)-propenoic acid, 1,3-dihydro-5-hydroxy-2H-indol-2-one, hexadecanoic acid, and oleic acid.

The results of the GC-MS analysis of the C. chinensis seedcoat extracts are provided in Fig. 2 and Table 3. Compared with the control levels, only the 1,2,3-benzenetriol relative content decreased during stratification. After a 45-d stratification, the relative 1,2,3-benzenetriol content was $0 \%$, which was lower than the corresponding control level $(90.0 \%)$. In

Table 1. Influence of the stratification duration on the effects of Cercis chinensis seed extracts on cabbage seed germination.

\begin{tabular}{lccc}
\hline Treatment & $\begin{array}{c}\text { Germination } \\
\text { percentage }(\%)\end{array}$ & $\begin{array}{c}\text { Decline in germination } \\
\text { percentage }(\%)\end{array}$ \\
\hline Control & 0 & $92.0 \pm 4.0 \mathrm{a}$ & 0.0 \\
Stratification duration (d) & 15 & $39.2 \pm 1.4 \mathrm{e}$ & 57.4 \\
& 30 & $44.8 \pm 3.7 \mathrm{~d}$ & 51.3 \\
& 45 & $60.8 \pm 3.7 \mathrm{c}$ & 33.9 \\
& 60 & $85.3 \pm 3.7 \mathrm{~b}$ & 7.3 \\
\end{tabular}

The germination percentage is provided as the mean $(\mathrm{n}=100 \times 3) \pm$ SD. Different letters indicate significant differences, which were determined based on Duncan's multiple range test $(P \leq 0.05)$. contrast, the relative contents of 13 other compounds increased during dormancy release.

The relative contents of seven compounds decreased in $C$. chinensis seeds during dormancy release (Tables 2 and 3). Saccharides and oleic acid are sources of energy during seed dormancy release and germination, implying they are not germination inhibitors. A previous study revealed that the $I C_{50}$ of hexadecanoic acid is 3,112.1 $\mu \mathrm{g} \cdot \mathrm{mL}^{-1}$ (Zhang, 2007), indicating it only has weak inhibitory effects on seed germination. Phenol compounds often are strongly inhibitory toward seed germination (Han et al., 2001; Samajdar et al., 2018; Zhao et al., 2018). In addition, $\mathrm{ABA}$ is an important plant hormone involved in many biological processes, including the regulation of seed dormancy and germination (Bian et al., 2018; Eliášová et al., 2015;
Samajdar et al., 2018). On the basis of the changes to their relative contents, 1,2,3-benzenetriol and ABA were identified as putative endogenous inhibitors of $C$. chinensis seed germination.

Determining the $I C_{50}$ of endogenous inhibitors. The inhibitory effect of 1,2,3-benzenetriol increased with increasing concentrations. For example, compared with the effects of the control (distilled water), cabbage radicle growth was inhibited by $23.5 \%$ and $75.3 \%$ in response to an exposure to 1 and $100 \mu \mathrm{g} \cdot \mathrm{mL}^{-1}$ 1,2,3-benzenetriol, respectively (Fig. 3A). Thus, exogenous 1,2,3-benzenetriol strongly inhibited cabbage seed germination, with an $I C_{50}$ of $51.2 \mu \mathrm{g} \cdot \mathrm{mL}^{-1}$. Our results proved that exogenous $\mathrm{ABA}$ is highly inhibitory toward cabbage seed germination, with an $I C_{50}$ of 1.5 ng. $\mathrm{mL}^{-1}$ (Fig. 3B).

Quantification of endogenous inhibitors in C. chinensis seeds during dormancy release. We investigated the dynamic changes to 1,2,3-benzenetriol and ABA during C. chinensis seed stratification via HPLC-MS. The data were converted to content per unit weight of seed (Fig. 4). The 1,2,3-benzenetriol content decreased significantly during dormancy release. Specifically, 1,2,3-benzenetriol content in the control was the highest $\left(561.4 \mu \mathrm{g} \cdot \mathrm{mL}^{-1}\right)$, and was 10 times greater than the $I C_{50}(51.2$ $\left.\mu \mathrm{g} \cdot \mathrm{mL}^{-1}\right)$. When the seeds were cold-stratified for $45 \mathrm{~d}$, the 1,2,3-benzenetriol content decreased to $25.9 \mu \mathrm{g} \cdot \mathrm{mL}^{-1}(95.4 \%$ decline $)$.
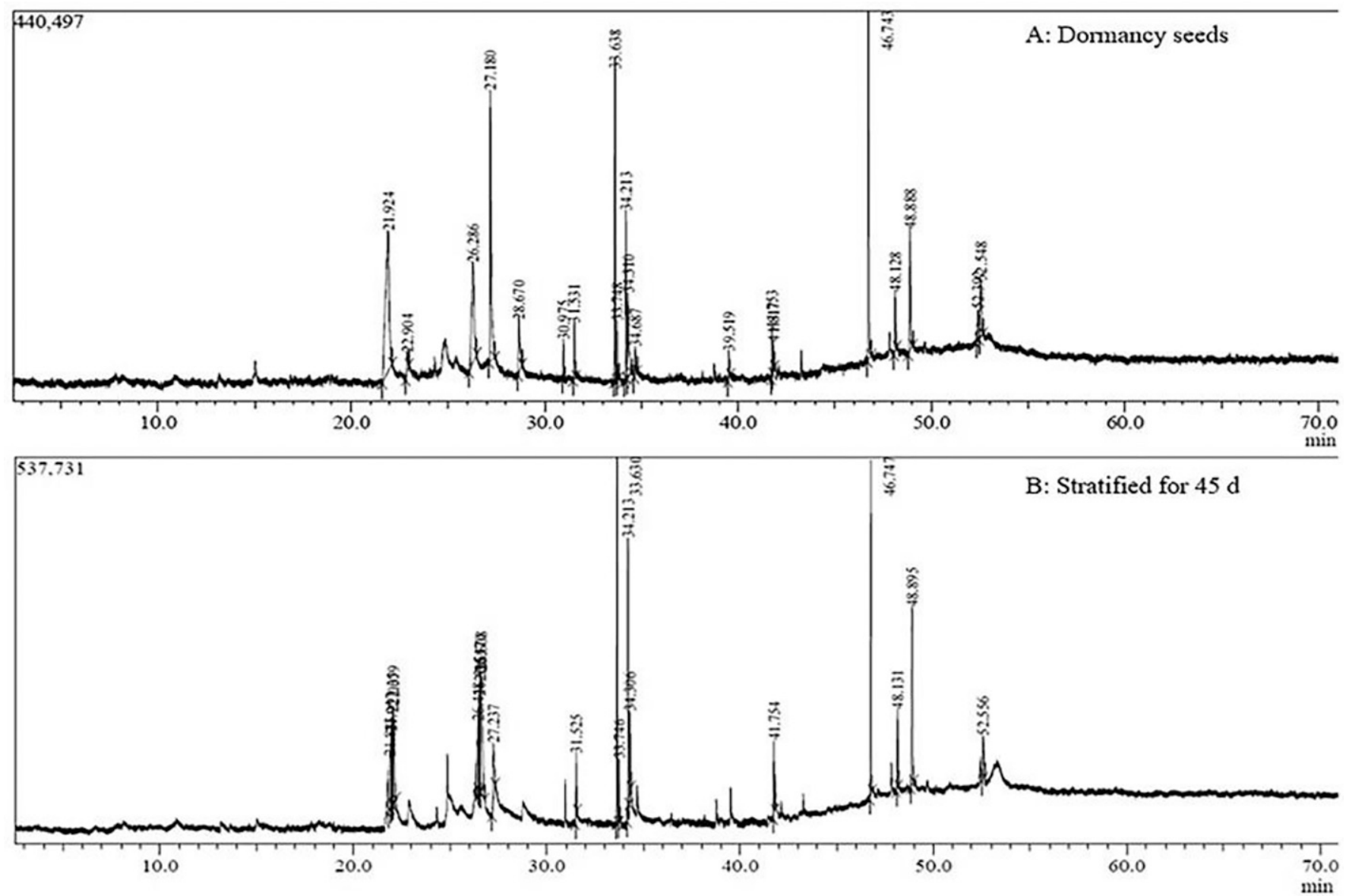

Fig. 1. Comparison of the gas chromatography-mass spectrometry chromatograms for the control and treated Cercis chinensis endosperms. 
Table 2. Changes to the relative Cercis chinensis endosperm contents revealed by gas chromatography-mass spectrometry.

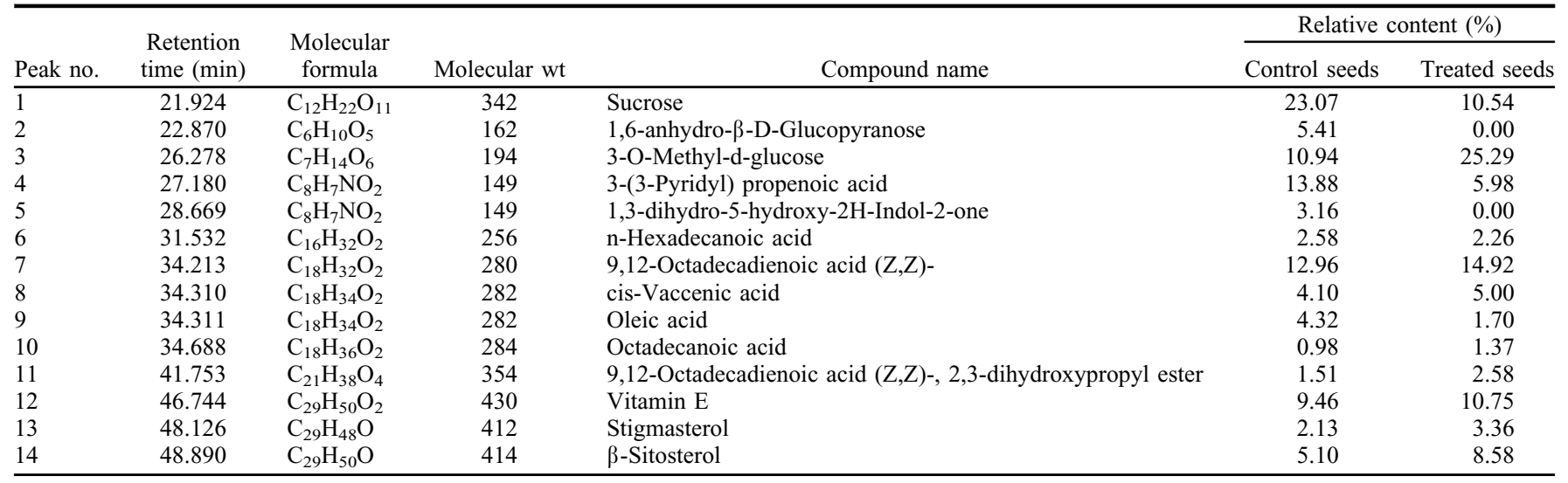

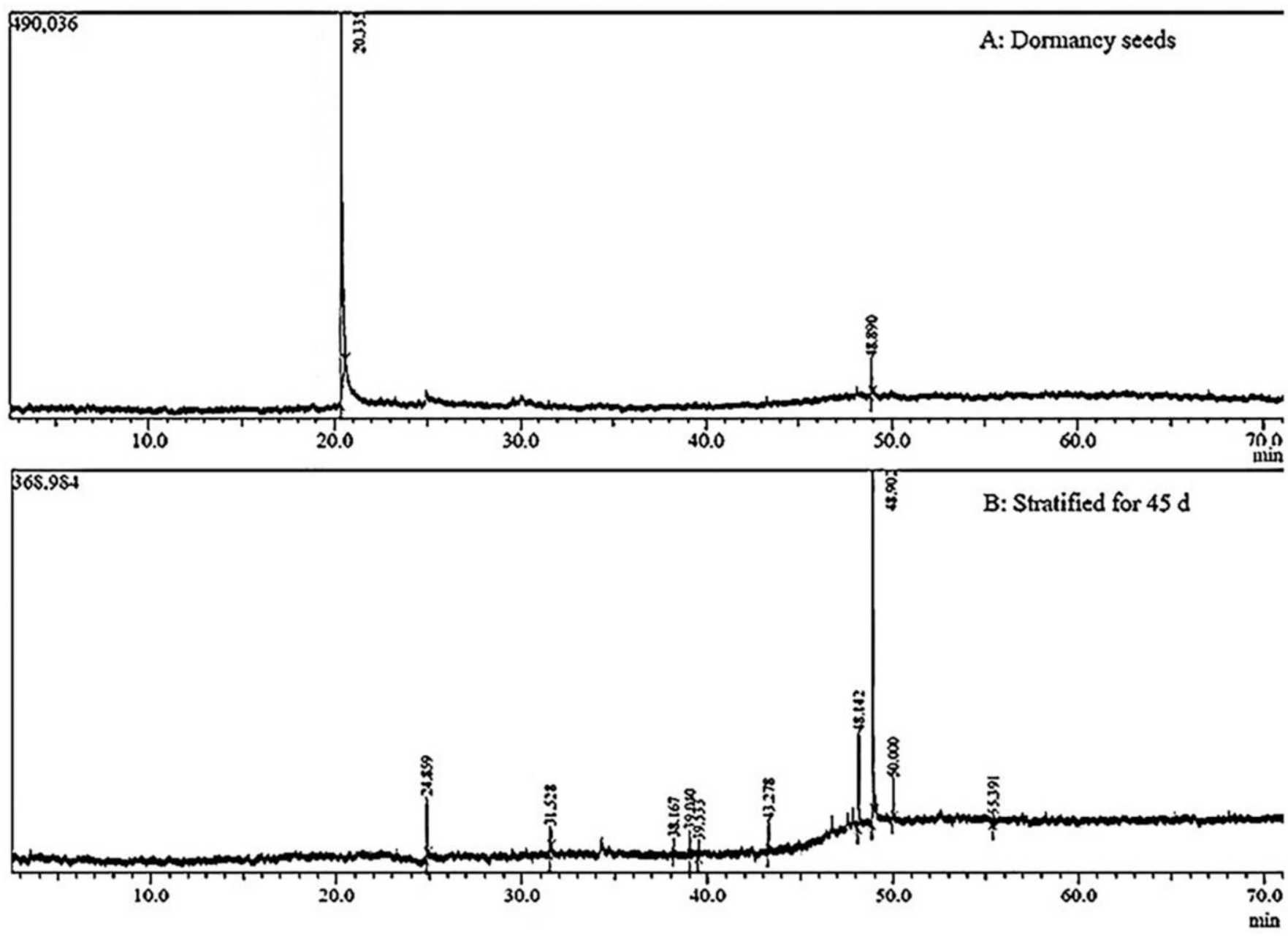

Fig. 2. Comparison of the gas chromatography-mass spectrometry chromatograms for the control and treated Cercis chinensis seedcoats.

When stratified for $60 \mathrm{~d}$, the 1,2,3-benzenetriol content decreased further to $17.7 \mu \mathrm{g} \cdot \mathrm{mL}^{-1}$. Thus, the cold stratification substantially decreased the 1,2,3-benzenetriol content (Fig. 4A).

The changes to the ABA content were similar to those of the phenol content (Fig. 4B). The control ABA content was highest $\left(5.6 \mathrm{ng} \cdot \mathrm{mL}^{-1}\right)$, and was five times greater than the $I C_{50}\left(1.5 \mathrm{ng} \cdot \mathrm{mL}^{-1}\right)$. However, the ABA content gradually decreased during dormancy release, reaching $0.9 \mathrm{ng} \cdot \mathrm{mL}^{-1}$ and $0.5 \mathrm{ng} \cdot \mathrm{mL}^{-1}$ after 45 - and 60 -d cold stratifications, respectively.

\section{Discussion}

Presence of endogenous inhibitors in the $C$. chinensis seeds. Although seed changes during physiological dormancy occur in many species, the exact metabolites or endogenous inhibitors underlying such changes remain largely unknown.
Some researchers believe many secondary metabolites in plant seeds can inhibit germination (Bian et al., 2018; Samajdar et al., 2018; Zhao et al., 2018). Wareing (1965) first detected endogenous inhibitors by testing the inhibitory effects of seed extracts on the germination of nondormant plant seeds. In the current study, the extracts of mature $C$. chinensis seeds seriously inhibited the germination of nondormant Chinese cabbage seeds. In addition, 
Table 3. Changes to the relative Cercis chinensis seedcoat contents determined by gas chromatography-mass spectrometry.

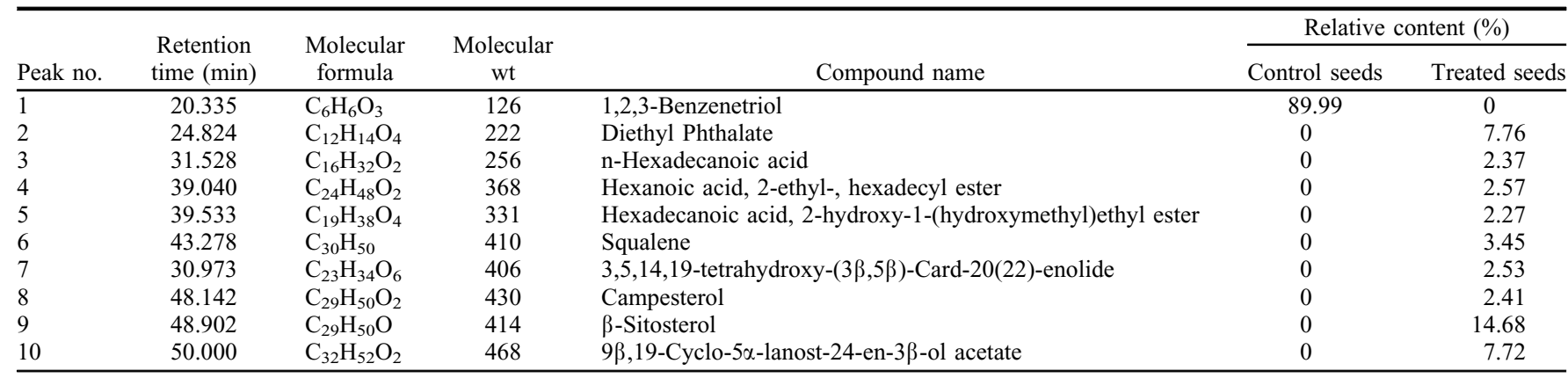
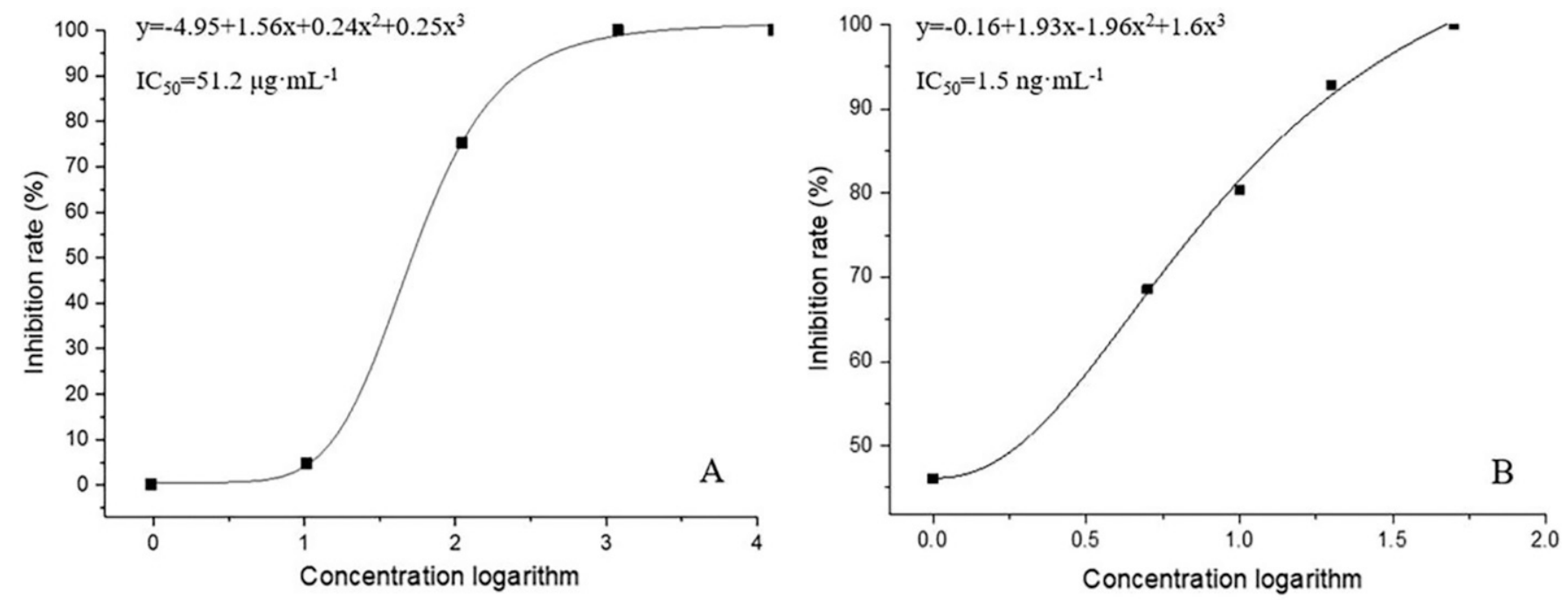

Fig. 3. Inhibitory effects of different concentrations of 1,2,3-benzenetriol (A) and abscisic acid (B) on cabbage seed radicle growth.
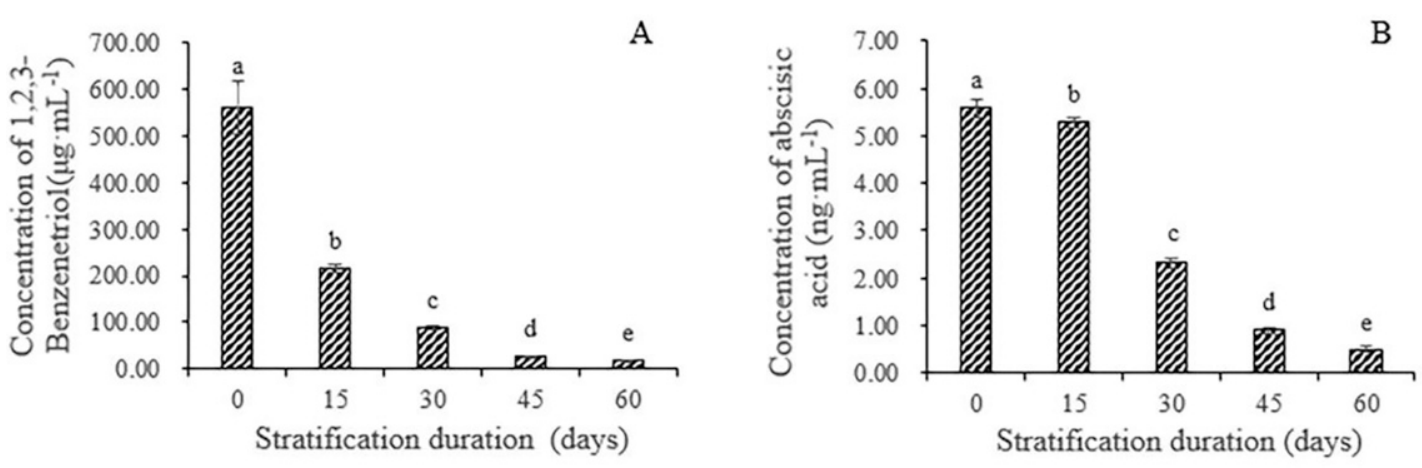

Fig. 4. Quantitative changes to the endogenous inhibitors 1,2,3-benzenetriol (A) and abscisic acid (ABA) (B) in Cercis chinensis seeds at five stratification stages $(0,15,30,45$, and $60 \mathrm{~d})$ during dormancy release. Data are presented as the mean $\pm \mathrm{SE}$ of three replicates. Different letters above bars indicate significant differences at $P \leq 0.05$ as determined by Duncan's multiple range test.

the inhibitory effects of the extracts gradually decreased as the duration of the cold stratification increased. These results imply C. chinensis seeds contain endogenous inhibitors, but the abundance of these inhibitors gradually decreases during dormancy release. This is consistent with the results of an earlier study by Bian et al. (2018), who reported that endogenous inhibitors are the most important factors affecting T. yunnanensis seed dormancy, and their contents gradually decrease during dormancy release.
Germination inhibitors in different seed parts. Endogenous inhibitors are widely distributed in various plant tissues, and are normally present in the embryo, endosperm, or seedcoat (Martinucci et al., 1985; Samajdar et al., 2018). Previous research indicated that excised embryos of $C$. chinensis lack endogenous inhibitors because they can germinate promptly (Zhou, 2016). An HPLC-MS analysis of the $C$. chinensis seedcoat revealed substantial changes to 1,2,3-benzenetriol during the seed stratification treatment, suggesting it is an endogenous inhibitor in the $C$. chinensis seedcoat. Similar results were reported in various other plant species, including Glycine soja (Zhou et al., 2010) and Grevillea petrophiloides (Ma et al., 2015), in which the seedcoat contains a major germination inhibitor. Our GC-MS analysis indicated that fatty acids are the major components in the C. chinensis endosperm, but they are weakly inhibitory toward seed germination. In this study, we only investigated the changes to the ABA content of whole seeds; however, the localization of ABA in $C$. chinensis remains uncharacterized. Therefore, future research 
should clarify the localization of ABA to determine whether the endosperm is associated with physiological dormancy.

Germination inhibitors in C. chinensis seeds. Phenolic compounds are important allelochemicals that strongly inhibit seed germination (Samajdar et al., 2018). Previous studies proved that phenolics hinder seed germination by competing with the embryo for oxygen (Samajdar et al., 2018; Zhou et al., 2010). In our study, the $I C_{50}$ of 1,2,3-benzenetriol was $51.2 \mu \mathrm{g} \cdot \mathrm{mL}^{-1}$, reflecting its strong inhibitory effect. Earlier studies confirmed that both 1,2-benzenediol, with an $I C_{50}$ of $39.8 \mu \mathrm{g} \cdot \mathrm{mL}^{-1}$ (Han et al., 2001), and BHT, with an $I C_{50}$ of $54.9 \mathrm{mg} \cdot \mathrm{mL}^{-1}$ (Zhao et al., 2018), are water-soluble endogenous inhibitors with strong inhibitory effects on seed germination.

$\mathrm{ABA}$ is one of the major plant hormones involved in many biological processes, especially in the regulation of seed dormancy and germination (Bian et al., 2018; Eliášová et al., 2015; Samajdar et al., 2018). Earlier studies concluded that ABA sensitivity is correlated with the extent of the dormancy of mature seeds (Bewley and Black, 1994). However, recent investigations suggested that dormancy release via stratification is highly correlated with changes to the ABA content (Chen et al., 2015; Gubler et al., 2005). In the current study, we detected a decrease in the ABA content of $C$. chinensis seeds from 5.6 $\mathrm{ng} \cdot \mathrm{mL}^{-1}$ to $0.5 \mathrm{ng} \cdot \mathrm{mL}^{-1}$ during dormancy release. Moreover, exogenous ABA had an extremely strong inhibitory effect on cabbage seed germination $\left(I C_{50}\right.$ of $\left.1.5 \mathrm{ng} \cdot \mathrm{mL}^{-1}\right)$. These results indicate that as an endogenous inhibitor, $\mathrm{ABA}$ is important for regulating the onset of seed dormancy, even though it is present in the seed at very low levels.

\section{Literature Cited}

Bewley, J.D. and M. Black. 1994. Dormancy and the control of germination, p. 199-271. In: J.D. Bewley and M. Black (eds.). Seeds. Springer, Boston, MA, doi: 978-0-306-44748-8.

Bian, F.Y., J.R. Su, W.D. Liu, and S.F. Li. 2018. Dormancy release and germination of Taxus yunnanensis seeds during wet sand storage. Sci. Rep. 8:3205, doi: 10.1038/s41598-018-21469-9.

Botinestean, C., N.G. Hadaruga, D.I. Hadaruga, and I. Jianu. 2012. Fatty acids composition by gas chromatography-mass spectrometry (GCMS) and most important physical-chemicals parameters of tomato seed oil. J. Agroalimentary Processes and Technol. 18(1):89-94.

Chen, H., J. Ruan, P. Chu, W. Fu, Z.W. Liang, and C.L. Li. 2019. AtPER1 enhances primary seed dormancy and reduces seed germination by suppressing the ABA catabolism and GA biosynthesis in Arabidopsis seeds. Plant J. 101 (2):310-323, doi: 10.1111/tpj.14542.

Chen, S.Y., S.H. Chou, C.C. Tsai, W.Y. Hsu, and L.L. Kuo-Huang. 2015. Effects of moist cold stratification on germination, plant growth regulators, metabolites and embryo ultrastructure in seeds of Acer morrisonense (Sapindaceae). Plant Physiol. Biochem. 94:165-173, doi: 10.1016/j.plaphy.2015.06.004.

Eliášová, K., B. Pešek, and Z. Vondráková. 2015. Storage compounds, ABA and fumarase in Fagus sylvatica embryos during stratification. Dendrobiology 74:25-33, doi: 10.12657/denbio.074.003.

Finch-Savage, W.E. and G. Leubner-Metzger. 2006. Seed dormancy and the control of germination. New Phytol. 171:501-523, doi: 10.1111/j.1469-8137.2006.01787.x.

Gubler, F., A.A. Millar, and J.V. Jacobsen. 2005. Dormancy release, ABA and pre-harvest sprouting. Curr. Opin. Plant Biol. 8(2): 183-187, doi: 10.1016/j.pbi.2005.01.011.

Han, D., X.L. Gao, Y.G. Huang, Q.L. Zhu, W. Liu, and R. Wang. 2001. Study on germination inhibitors in different parts of american ginseng fruit. Special Wild Economic Animal and Plant Research 23(2):13-18. (In Chinese), doi: 10.16720/j.cnki.tcyj.2001.02.005.

Hu, X.W., X.H. Huang, and Y.R. Wang. 2012. Hormonal and temperature regulation of seed dormancy and germination in Leymus chinensis. Plant Growth Regulat. 67:199-207, doi: 10.1007/s10725-012-9677-3.

International Seed Testing Association (ISTA). 2020. International rules for seed testing. International Seed Testing Association. Chapter 5: The germination test, p. 1-3. Bassersdorf, Switzerland. Online ISSN 2310-3655.

Li, H.L. 1944. Taxonomy and distribution of the genus Cercis in China. Bull. Torrey Bot. Club 71(4):419-425.

Ma, X., J. Guo, X. Han, and G.J. Yan. 2015. Grevillea (Proteaceae) seed coats contain inhibitors for seed germination. Aust. J. Bot. 63(7): 566-571, doi: 10.1071/BT15085.

Martinucci, R., P. Gastaldo, P. Profumo, and L.R. Bevilacqua. 1985. Bound ferulic acid in the endosperm of Cercis siliquastrum L. Plant Sci. 38:41-46, doi: 10.1016/0168-9452(85)90077-9.

Matok, H., B. Leszczyński, G. Chrzanowski, and C. Sempruch. 2009. Effect of walnut phenolics on germination of dandelion seeds. Allelopathy J. 24(1):177-182, doi: 10.2134/agronj2008.0180x.
Nasrin, M.S., F. Jesmin, M.M. Rahman, and M.F. Alam. 2016. Seed germination potential, phytochemical analysis and antioxidant activity of two tomato varieties. Intl. J. Biosci. 8(1): 63-76, doi: 10.12692/ijb/8.1.63-76.

Paiva, R. and D. Prudente. 2018. Seed Dormancy and Germination: Physiological Considerations. J. Cell Dev. Biol. 2:1-2, doi: 10.1007/ 978-981-13-2023-1_28.

Poljakoff-Mayber, A., I. Popilevski, E. Belausov, and Y. Ben-Tal. 2002. Involvement of phytohormones in germination of dormant and nondormant oat (Avena sativa L.) seeds. Plant Growth Regulat. 37:7-16, doi: 10.1023/A: 1020328407147.

Robertson, K.R. 1976. Cercis: The redbuds. Arnoldia. 36(2):37-49.

Samajdar, S., S. Mukherjee, and P.P. Das. 2018. Seed germination inhibitors: Molecular and phytochemical aspects. Intl. J. Appl. Pharm. Sci. Res. 3:12-23, doi: 10.21477/ijapsr. v3i02.11365.

Shao, C., J.Y. Liu, S.N. Zhang, and Y.Y. Zhang. 2016. Bioassay of endogenous germination inhibitors in Trillium kamtschaticum seed. Seed Sci. Technol. 44:1-9, doi: 10.15258/sst.2016.44.1.16.

Wang, J.T., G.Q. Wu, and X.P. Ju. 2009. Study on antioxidant activity of extracts from flowers of Cercis chinensis Bunge. in vitro. Chemistry and Bioengineering. 26(1):41-43.

Wareing, P.F. 1965. Endogenous inhibitors in seed germination and dormancy, pp. 2556-2571. In: Lang A. (ed.). Differenzierung und Entwicklung / Differentiation and Development. Handbuch der Pflanzenphysiologie / Encyclopedia of Plant Physiology, vol. 15. Springer, Berlin, Heidelberg, doi: 10.1007/978-3-642-50088-6_64.

Zhang, Y., L. Zhang, T. Li, and Y. Gao. 2011. Study on the anti-inflammatory and analgesic effect of the Cercis chinensis Bunee leaves and cortices. Chin. J. Hosp. Pharm. 31:45-47.

Zhang, Y.J. 2007. Studies on seed dormancy mechanism of Taxus chinessis var. mairei. Nanjing Forestry University. (In Chinese).

Zhao, T.T., C.M. Qian, Y.P. Gao, L. Chen, M.W. Zhu, Y. Pan, and S.X. Li. 2018. Germination inhibitors detected in Sapium sebiferum seeds. J. For. Res. 30(6):2305-2312, doi: 10.1007/ s11676-018-0798-z.

Zhou, J. 2016. The mechanism of water absorbing and dormancy in Cercis chinensis seeds. Nanjing Forestry University. (In Chinese).

Zhou, S., H. Sekizaki, Z. Yang, S. Sawa, and J. Pan. 2010. Phenolics in the seed coat of wild soybean (Glycine soja) and their significance for seed hardness and seed germination. J. Agr. Food Chem. 58(20):10972-10978, doi: $10.1021 /$ jf102694k. 